НОСИКОВ Андрей Андреевич - соискатель ученой степени в Российской академии народного хозяйства и государственной службы при Президенте РФ (119571, Россия, г. Москва, nр-кт Вернадского, 82, стр. 1; a.a.nosikov@gmail.com)

\title{
К КОНЦЕПЦИИ ЦИФРОВЫХ ИНСТИТУТОВ: КАК ПОСРЕДСТВОМ ТЕХНОЛОГИИ БЛОКЧЕЙНА МОЖНО МОДЕРНИЗИРОВАТЬ ИНСТИТУЦИОНАЛЬНЫЕ ПРАКТИКИ
}

Аннотация. Статья посвящена возможности применения технологического подхода при модернизации политических и государственных институтов. Исходя из технологических особенностей блокчейна автор предлагает модельный проект 5 этапов модернизации институтов, предусматривающих внедрение технологии блокчейна в качестве технологической основы для обеспечения деятельности политических и государственных институтов. Автор выделяет особенности и гипотетические положительные эффекты от внедрения каждого из этапов.

Ключевые слова: блокчейн, смарт-контракт, политические институты, государственные институты, модернизация, цифровые институты

$\mathrm{C}$ егодняшняя РФ сталкивается с институциональным кризисом. Так, индексы институционального доверия практически всем институтам - от судов до выборных представительных органов власти (за исключением президента, спецслужб и армии) - находятся в отрицательном значении уже не первый год ${ }^{1}$. Консалтинговые агентства также отмечают тотальное недоверие граждан РФ к государственным институтам ${ }^{2}$. Этим процессам сопутствует рост бюрократии: численность чиновников, обслуживающих государственные органы и органы местного самоуправления, возросла с 1,1 млн чел. в 2000 до 2,1 млн в $2018^{3}$. Синхронно с ростом обслуживающей институты бюрократии РФ продолжает опускаться в рейтинге восприятия коррупции с 82-го места в 2000 до 137-го в 2019 г. ${ }^{4}$ Одновременно с этим возникают такие технологии, которые потенциально способны радикальным образом преобразовать институциональные практики. И одной из таких технологий является блокчейн, предполагающий в своей основе на техническом уровне транспарентность и неизменность результатов [Iansiti, Lakhani 2017: 123; Crosby et al. 2016: 9] (невозможность подмены данных и осуществления иных фальсификаций), обеспечение актуальной версии данных для всех членов блокчейн-сети, возможность децентрализованного хранения и обработки данных [Zheng et al. 2018: 357], a также возможность обеспечения полной анонимности пользователей, что требуется при проведении выборов и иных плебисцитов. И особенно актуальной данная проблематика является именно в контексте РФ как страны одновременно с достаточно высоким уровнем проникновения Интернета и с критически низким уровнем доверия к существующим политическим институтам.

\footnotetext{
1 Институциональное доверие. - Левада-Центр. Доступ: https://www.levada.ru/2018/10/04/ institutsionalnoe-doverie-4/ (проверено 25.05.2020).

2019 Edelman trust barometer: global report. - Edelman. URL: https://www.edelman.com/sites/g/files/ aatuss191/files/2019-02/2019_Edelman_Trust_Barometer_Global_Report.pdf (accessed 25.05.2020).

3 Государство, общественные организации. - Федеральная служба государственной статистики. Доступ: https://www.gks.ru/folder/11191 (проверено 25.05.2020).

4 Россия в Индексе восприятия коррупции-2019: 28 баллов и 137 место. - Transparency International Россия. Доступ: https://transparency.org.ru/research/indeks-vospriyatiya-korruptsii/rossiya-v-indeksevospriyatiya-korruptsii-2019-28-ballov-i-137-mesto.html (проверено 25.05.2020).
} 
Стоит особо отметить, что представленные в данной статье модели являются скорее предварительным модельным эскизом, дающим основу для широкой, невозможной в рамках одной статьи дискуссии относительно цифровизации институтов в целом и особенностей применения отдельных технологических решений, таких как блокчейн, в частности.

Эman 1. Перевод государственных реестров, баз данных и государственного документооборота на блокчейн. Перевод государственных реестров и баз данных на технологию блокчейна позволит значительно повысить как качество предоставления государственных услуг, так и качество государственных институтов в целом. Во-первых, у всех пользователей баз данных на блокчейне всегда будет актуальная версия данных. Во-вторых, будет невозможна подмена данных в базах постфактум, что продиктовано самой архитектоникой блокчейна. В-третьих, децентрализованное хранение данных позволит обеспечить стратегическую устойчивость инфраструктуры в случае наступления чрезвычайных ситуаций. В-четвертых, снизится влияние человеческого фактора на процессы ведения документооборота и хранения данных, как следствие, понизится коррупциоемкость данных процессов 1 .

В качестве успешного примера частичной реализации данного этапа можно привести опыт совместного сотрудничества таможенных органов Азербайджана и корпорации IBM по переводу баз данных таможенной системы на блокчейн. Данная мера позволит таможенным органам по умолчанию иметь всегда актуальную информацию о грузах без каких-либо дополнительных обращений или запросов ${ }^{2}$. Помимо этого, применение блокчейна в данной отрасли «исключает возможность подмены или записи задним числом данных», что «минимизирует коррупционные риски и гарантирует неизменность информации, а также позволяет отследить все взаимодействия» ${ }^{3}$. Очевидно, что это лишь начало глобальной цифровой трансформации реестров и баз данных, а также методов взаимодействия госорганов и институтов с информацией. Несложно представить реестр с информацией о гражданах или единую базу данных на блокчейне, которую невозможно фальсифицировать, или базу, в которую в реальном времени стекаются все голоса на выборах (минуя при этом УИКи, ТИКи и человека в качестве арбитра и посредника).

Эman 2. «Токенизация» ${ }^{4}$ гражданства. Так как блокчейн - это в первую очередь реестр, хотя и устроенный особым образом, необходимо перевести привычные нам категории в соответствие с цифровой логикой, сделав их пригодными для записи в блокчейн-реестр. И именно токенизация является таковой процедурой. Токенизация, в свою очередь, - это процесс наделения реальных ценностей (например, права владения имуществом, деньги, ценные бумаги и т. д.) соответствующими им токенами, отражающими эти ценности в блокчейн-реестре. У граждан существует ряд ценностей, являющихся гражданскими правами, а также ряд ценностей, предоставляемых им государством в рамках социальной защиты граждан. Для того чтобы включить эти права в систему, где институциональные правила исполняются посредством смарт-контрактов,

\footnotetext{
1 Отчет с круглого стола «Применение блокчейн-технологий в антикоррупции». - Высшая школа экономики. 31.05.2017. Доступ: https://lap.hse.ru/news/206331766.html (проверено 25.05.2020).

2 В Баку обсуждают внедрение современных технологий в таможенной сфере. - Sputnik. Азербайджан. Доступ: https://az.sputniknews.ru/economy/20190612/420729837/tamozhnja-informacionnye-tehnologiiblokchejn.html (проверено 24.05.2020).

3 Лапшина А. 2019. Блокчейн и таможня: как технология меняет международную торговлю. - LetKnow News. Доступ: https://letknow.news/publications/blokcheyn-i-tamozhnya-kak-tehnologiyamenyaet-mezhdunarodnuyu-torgovlyu--24924.html (проверено 24.05.2020).

4 Токен (от англ. token - знак, символ) - это цифровая условная единица учета, представляющая сбой запись в блокчейн-реестре.
} 
программ, функционирующих на базе блокчейна и совершающих определенные алгоритмы действий при наступлении заданных условий, что позволяет автоматически и необратимо совершать всевозможные сделки с цифровыми активами (токенами) без привлечения третьих лиц [Luu et al. 2016: 254], необходимо сперва токенизировать гражданские (и иные) права, перевести их из категории права в «цифру», в категорию, понятную реестру. Например, одному голосу на выборах может соответствовать один конкретный токен. Когда гражданин передает программе смарт-контракта свой токен голоса, указывая, что он передает эту условную единицу в пользу конкретного кандидата, программа, автоматически сверив наличие у гражданина избирательного права, записывает в блокчейн-реестр, что данному кандидату поступил голос. При этом возможно обеспечение полной анонимности голоса, поскольку верификация осуществляется смарт-контрактом (программой, а не человеком): в блокчейн с результатами выборов записываются уже полностью обезличенные данные. Вообще токенизации можно подвергнуть множество отраслей, повысив таким образом безопасность, скорость и нивелировав потенциальную коррупциоемкость значительного числа сделок и операций в самых разных сферах экономической и общественной деятельности.

Эman 3. Смарт-контракт вместо чиновника. Когда ценности соотнесены с токенами, появляется более безопасный, быстрый и прозрачный способ осуществления сделок с цифровыми активами (под цифровыми активами подразумеваются многие токенизированные ценности - от права голоса до права на получение наследства или социального пособия). Неизменная и линейная логика смарт-контрактов идеально подходит для российской нормативно-правовой системы. Например, если по закону гражданин вступает в права наследования после смерти родственника, то такому случаю может соответствовать определенный тип смарт-контракта, который при наступлении определенных условий (к примеру, смерть родственника при родстве субъектов и отсутствии заверенного цифровой подписью завещания) автоматически передает права владения.

Эman 4. Выборы и блокчейн. Блокчейн позволяет технически реализовать нефальсифицируемое голосование, где посредством смарт-контрактов достигается полная анонимность процесса при соблюдении всех законных формальностей без возможности вмешательства третьих лиц в процесс, что способно сделать фальсификации на выборах попросту невозможными и бессмысленными. Однако для реализации данного сценария необходимо обеспечить полную открытость и прозрачность для широкого общественного аудита всех этапов проектирования и создания такой системы - от написания концепции и технического задания до написания кода и запуска. При этом особенно важно отметить, что в этом случае блокчейн должен обязательно обладать открытым программным кодом с целью обеспечения независимой гражданской экспертизы технической части системы. Кроме того, открытый код позволит вовлечь в совершенствование продукта и поиск ошибок множество независимых энтузиастов. Данное условие является крайне важным, поскольку в условиях кризиса доверия к государственным институтам многие государственные инициативы могут восприниматься гражданами с недоверием. Примером тому может служить кейс по экспериментальному проведению электронного голосования на выборах в Мосгордуму в электоральном цикле 2019 г., скомпрометированный по ряду причин, возникших вследствие закрытости процедуры разработки и внедрения данной системы от широкой общественности. Прежде всего, наиболее серьезным обвинением в адрес проводимого мэрией Москвы эксперимента со стороны общественно- 
сти является отсутствие фактической анонимности ${ }^{1}$. Таким образом, запустив систему электронного голосования без широкого общественного аудита (проводившихся тестов оказалось явно недостаточно), в закрытом режиме, вместо технологии, способствующей транспарентности электорального процесса, мэрия Москвы, по словам критиков системы электронного голосования, создала систему, «результаты которой можно нарисовать и нельзя проверить» ${ }^{2}$. В итоге у мэрии Москвы прошли пикеты за отмену итогов электронного голосования ${ }^{3}$, ряд кандидатов добиваются отмены итогов электронного голосования через суд 4 , а сама идея электронного голосования в России, похоже, оказалась надолго дискредитированной. Но несмотря на описанный выше кейс неудачного эксперимента по внедрению электронного голосования на выборах в Мосгордуму, существуют примеры успешного применения технологии блокчейна для проведения электоральных процедур 5 .

Кроме того, посредством блокчейна можно усовершенствовать не только непосредственно акт плебисцита, но и множество сопряженных с электоральным процессом процедур. Так, к примеру, при наличии единой базы данных с информацией о гражданах на блокчейне (см. этап 1) возможен сбор подписей за выдвижение кандидатов посредством электронных подписей и смартконтрактов, что делает данный процесс нефальсифицируемым и верифицируемым без вмешательства третьих лиц. То есть, на техническом уровне база данных на блокчейне всегда остается единой и актуальной для всех участников процесса, а смарт-контракт исключает из процесса сбора подписей третьих лиц, что нивелирует человеческий фактор (и, как следствие, потенциальный конфликт интересов и коррупцию). При этом данный процесс становится для подписанта полностью анонимным, поскольку сверка его электронной подписи и криптографического ключа с базой данных (посредством базы данных смарт-контракт автоматически определяет наличие у гражданина соответствующего права, например, достижения гражданином совершеннолетия и проживания на территории муниципалитета, в который избирается кандидат). Последующая передача голоса-токена (токенизированной подписи за выдвижение кандидата) в пользу кандидата осуществляется внутри программы смартконтракта, без какого-либо человеческого участия. Поскольку процесс сверки автоматизирован, на выходе из смарт-контракта третьи лица могут видеть лишь результат: «кандидат Х получает подпись».

На идее быстрых, защищенных и прозрачных голосований базируется еще одна концепция под названием «крипторегулирование» (crypto-governance) [McKie 2018], в основе которой лежит идея о симбиозе принципов прямой демократии с технологической базой блокчейна с целю обеспечения более

1 Официально: у нас есть то, чего быть не должно. «Электронное голосование» полностью скомпрометировано. - Навальный. Доступ: https://navalny.com/p/6234/ (проверено 25.05.2020); ФБК получил личные данные всех интернет-избирателей на выборах в Мосгордуму, но мэрия это отрицала. Мы доказали, что список настоящий. - Meduza. Доступ: https://meduza.io/feature/2019/10/11/fbkpoluchil-lichnye-dannye-vseh-internet-izbirateley-na-vyborah-v-mosgordumu-no-meriya-eto-otritsala-mydokazali-chto-spisok-nastoyaschiy/ (проверено 25.05.2020).

2 Распопов А. В. 2019. Москве начались одиночные пикеты за отмену электронного голосования. Новая газета. Доступ: https://www.novayagazeta.ru/news/2019/09/12/155266-v-moskve-nachalisodinochnye-pikety-za-otmenu-elektronnogo-golosovaniya/ (проверено 25.05.2020).

3 Там же.

4 Участник выборов в Мосгордуму оспорил в суде результаты электронного голосования. - Ведомости. Доступ: https://www.vedomosti.ru/politics/news/2019/09/18/811532-v/ (проверено 25.05.2020).

5 В Сьерра-Леоне прошли первые в мире президентские выборы с использованием технологии блокчейн. - ForkLog. Доступ: https://forklog.com/v-serra-leone-proshli-pervye-v-mire-prezidentskievybory-s-ispolzovaniem-tehnologii-blokchejn/ (проверено 25.05.2020). 
справедливой [Zurrer 2019], демократической и прозрачной системы принятия решений в самых различных сферах - от общественных отношений до бизнеспроцессов. Таким образом, обеспечение функционирования институтов выборов посредством блокчейна может стать лишь первым звеном в глобальном процессе изменений в процессах выработки решений и контроля за их имплементацией.

Эman 5. Цифровые институты. Функционирование старых институтов хоть и регламентировалось законом или же общественными договоренностями, но опиралось на бюрократический аппарат, обеспечивающий функционирование и обслуживание данных институтов.

Смоделированные выше этапы внедрения блокчейн-технологий в институциональные процессы, модернизируя существующую институциональную среду, попутно формируют и новый тип институтов - цифровые институты.

Цифровые институты - это институты, конфигурации и правила функционирования которых по-прежнему определяются посредством общественного договора, однако за имплементацию выработанных правил в процессах функционирования данных институтов отвечают не третьи лица (чиновники, обслуживающий персонал, иные арбитры и т.д.), а программные алгоритмы с их неизменной и заранее определенной в ходе выработки институциональных правил логикой.

Деятельность цифровых институтов все так же продиктована законом или иными правилами, выработанными в ходе достижения общественного консенсуса (хотя гипотетически не существует никаких преград для внедрения цифровых институтов и в условиях авторитарных режимов, когда правила их функционирования диктуются авторитарной властью, а цифровые институты лишь инструментально снижают бюрократические издержки, коррупцию и политические риски, возникающие в связи с невозможностью надлежащего исполнения традиционной бюрократией возложенных на нее задач по достижению стратегических приоритетов), однако за имплементацию законности в процессе функционирования данных институтов отвечает блокчейн как инструмент, в основе которого лежат неизменные правила и математические алгоритмы. Это делает цифровые институты по-настоящему беспристрастными, их обслуживание не требует содержания огромного штата чиновников или обширного бюрократического аппарата, вмешательство третьих сторон в процессы функционирования цифровых институтов сведены к минимуму вследствие широкого использования самоисполняемых «умных» контрактов, что, в конечном итоге, приводит к созданию «нового способа достижения общественного консенсуса, когда процедуры принятия решений базируются на принципах, обусловленных кодом» [Zurrer 2019]. Все это приводит к теоретической возможности возникновения новой системы государственного и общественного управления, когда институты инструментально обслуживаются и администрируются не бюрократией, а софтом, в который заложены четкие алгоритмы и правила, неизменные и единые для всех. Таким образом, концепция цифровых институтов является некой идеальной теоретической моделью цифровизации общественных, политических и экономических отношений, к которой необходимо стремиться при реализации смоделированных этапов.

В заключение же стоит отметить, что процессы цифровизации институтов в условиях РФ неизменно столкнутся с трудностями имплементации (как мы это могли наблюдать в кейсе московского электронного голосования), обусловленными как общей управленческой некомпетентностью, так и возникающим конфликтом традиционной бюрократии и стремящейся ее заменить цифровой. Данный конфликт является абсолютно естественным, поскольку 
множившейся, наращивающей свое влияние и власть на протяжении последних десятилетий бюрократии вряд ли понравится идея их замены цифровыми сервисами, программными алгоритмами (смарт-контракты) и нефальсифицируемыми реестрами (блокчейн). Однако, по Фукуяме, перед лицом вызовов (а цифровизация и сетевизация - это, безусловно, вызов для сегодняшних, сущностно спроектированных столетия назад институтов) институты либо эволюционируют, либо приходят в упадок [Фукуяма 2017: 592]. И здесь на сегодняшний день задача сообщества (и научного, и общественно-политического, и гражданского общества в целом) состоит именно в выработке и конструировании возможных дизайнов, обеспечивающих цифровизацию при наименьшей турбулентности переходного процесса, что, безусловно, открывает обширное поле для дальнейших дискуссий.

\section{Список литературы}

Фукуяма Ф. 2017. Угасание государственного порядка. М.: АСТ. 704 с.

Crosby M., Nachiapan, Pattanayak P., Verma S., Kalyanaraman V. 2016. Blockchain Technology: Beyond Bitcoin. - Applied Innovation. No. 2. P. 6-19.

Iansiti M., Lakhani K.R. 2017. The Truth about Blockchain. - Harvard Business Review. Vol. 1. No. 95. P. 118-127.

Luu L., Chu D.H., Olickel, H., Saxena P., Hobor A. 2016. Making Smart Contracts Smarter. - Proceedings of the 2016 ACM SIGSAC Conference on Computer and Communications Security. P. 254-269.

McKie S. 2018. The Crypto Governance Manifesto. - Medium. Доступ: https:// medium.com/amentum/the-crypto-governance-manifesto-7c40df928b04/ (проверено 25.05.2020).

Zheng Z., Xie S., Dai H.N., Chen X., Wang H. 2018. Blockchain Challenges and Opportunities: A survey. - International Journal of Web and Grid Services. Vol. 4. No. 14. P. 352-375.

Zurrer R. 2019. The Crypto-Governance Age Is Here. - Breaker mag. Доступ: https://breakermag.com/the-age-of-crypto-governance-is-upon-us/ (проверено 25.05.2020).

\section{ON THE CONCEPT OF DIGITAL INSTITUTIONS: HOW BLOCKCHAIN TECHNOLOGY CAN UPGRADE INSTITUTIONS}

\footnotetext{
Abstract. This article is devoted to the possibility of applying a technological approach to the modernization of political and state institutions, in particular the use of blockchain technology as a technological platform for the modernization of political and state institutions. Based on the technological features of the blockchain technology, the author models projects of five stages of the modernization of institutions. All these stages consider blockchain technologies as the technological basis for the functioning of political and state institutions. The author highlights features and hypothetical positive effects of the implementation of each of the modeled stages. Moreover, the models of stages 1-4 are applied solutions, while stage 5 is a theoretical attempt to simulate probabilistic scenarios of the transformation of institutions and the state as a result of the implementation of the previous stages, which leads to the emergence of the concept of digital institutions. The article provides a definition of digital institutions and some features of this concept.
}

Keywords: blockchain, smart contract, political institutions, government institutions, modernization, digital institutions 